\title{
Media Pembelajaran Interaktif Artyculate Storyline Meningkatkan Motivasi Dan Kompetensi Belajar Peserta Didik Pada Saat Pembelajaran Jarak Jauh
}

\author{
Agung Triono \\ SMA Negeri 1 Kabupaten Pandeglang
}

Corresponding Author: agungtriana@gmail.com

\begin{tabular}{|c|c|}
\hline & ABSTRACT \\
\hline & $\begin{array}{l}\text { The low motivation and competence of students in distance learning is } \\
\text { because teachers have not used interesting learning media in the learning } \\
\text { process. This has an impact on the learning outcomes to be achieved. } \\
\text { Overcoming these problems the author uses the interactive learning } \\
\text { media Artyculate Storyline to increase the motivation and learning } \\
\text { competence of students. This interactive learning media can be used as a } \\
\text { learning resource and support distance learning, as well as helping to } \\
\text { facilitate the delivery of material with additional competency features, } \\
\text { quizzes, learning videos, and glossaries that can be accessed offline and } \\
\text { online with ease of use on the web that has been provided. This } \\
\text { interactive learning media is also declared effective and can increase the } \\
\text { competence of students by } 5.39 \% \text {. The author also creates an interactive } \\
\text { learning media Articulate Storyline and applies it in learning process. }\end{array}$ \\
\hline $\begin{array}{l}\text { Kata Kunci } \\
\text { Keywords }\end{array}$ & $\begin{array}{l}\text { Artyculate Storyline 3, KKM, Interactive Media, Online learning, Effective } \\
\text { learning }\end{array}$ \\
\hline How to cite & (2021). Jurnal Ability, 2(4). \\
\hline
\end{tabular}

\section{PENDAHULUAN}

Penelitian-penelitian yang terkait dengan media pembelajaran interaktif Artyculate Storyline mampu meningkatkan motivasi belajar peserta didik pernah disampaikan di dalam beberapa penelitian di antaranya; (Setyaningsih dan Rusijono, 2020; Sukmarini dkk, 2021; Fitri , 2021; Pranata dkk, 2021; Pradani , 2021; Suhailah dkk, 2021). Penelitian dilakukan untuk meningkatkan motivasi belajar peserta didik dan berdampak pula pada peningkatan hasil belajar peserta didik pada kelas XI IPA SMA Negeri 1 Kabupaten Pandeglang pada mata pelajaran ekonomi lintas minat materi pendapatan nasional tahun 2021.

Pada saat pandemic covid 19 belajar dan pembelajaran dilakukan dari rumah secara pembelajaran jarak jauh, berbagai permasalahan ditemukan oleh guru selama pembelajaran jarak jauh antara lain turunnya motivasi belajar peserta didik sesuai dengan penelitian diantaranya, (Azzahra dkk, 2021; Zaitun dkk, 2020; Yasmini, 2021), terbatasanya kuota internet, kurangnya kerja sama antara orang tua dan peserta didik sesuai penelitian ( Haryono dan Sunhaji, 
Ability : Journal of Education and Social Analysis

Volume 2, Issue 4, Oktober 2021

Page : $31-41$

2021; Nuriana dan Adelina, 2021; Muzzamil, 2021), selain itu media pembelajaran yang di gunakan membosankan dan kurang menarik sejalan dengan penelitian ( Indiani, 2020; Kurniasari dkk, 2020; Yuangga dan Sunarsi, 2020), sehingga tujuan pembelajaran banyak yang belum tercapai. Penelitihan ini dilakukan pada pembelajaran Ekonomi lintas minat materi Pendapatan Nasional di kelas XI IPA SMA Negeri 1 Kabupaten Pandeglang pada tahun 2021.

Melihat permasalahan tersebut penulis menggunakan aplikasi media pembelajaran interaktif articulate storyline dalam pembelajaran jarak jauh agar lebih menarik serta dapat meningkatkan motivasi dan kompetensi belajar peserta didik. Penelitian ini penting dilakukan untuk memberikan gambaran yang jelas dalam pembelajaran jarak jauh menggunakan media pembelajaran interaktif articulate storyline agar tujuan pembelajaran dapat tercapai sesuai dengan rencana pembelajaran yang ditetapkan.

\section{METODE PENELITIAN}

Metode Penelitian ini menggunakan analisis deskriptif. Teknik pengumpulan data melalui angket dan wawancara. Waktu Penelitian mulai bulan Juli sampai dengan Oktober 2021. Objek penelitian penulisan ini peserta didik di SMA Negeri 1 Kabupaten Pandeglang. Populasi penelitian sejumlah 6 kelas atau peserta didik kelas XI IPA 1 sampai dengan XI IPA 6, karena peneliti mengajar di kelas tersebut. Menurut (Sugiyono, 2016) Metode penelitian deskriptif dan metode angket digunakan untuk mengetahui dan mempelajari data dari sampel yang diambil dari populasi. Dengan metode ini diperoleh data atau informasi kejadian-kejadian relatif, distribusi, serta hubungan-hubungan antar variable.

Tahapan penelitian penulis mendeskripsikan Articulate storyline sebagai media pembelajaran interaktif dalam pembelajaran jarak jauh di SMA Negeri 1 Kabupaten Pandeglang melalui tiga tahapan, tahapan tersebut antara lain: pertama, tahap perencanaan dimulai pada pertengahan bulan Juli 2021 tujuannya mengidentifikasi perumusan permasalahan yang diperoleh dari pembelajaran jarak jauh. Kedua, tahap pelaksanaan yang selanjudnya dicari beberapa alternative solusi menjawab rumusan masalah media pembelajaran tertentu yang digunakan mata pelajaran ekonomi yaitu media pembelajaran interaktif articulate storyline. Hal ini sejalan dengan pemikiran jika pertanyaan yang muncul atas masalah yang ada maka perlu dijawab dan dikaji secara ilmiah menurut Muri Yusuf, (2017). Hasil penggalian data menggunakan survey/angket, test tertulis, study dokumentasi dan observasi. Ketiga, tahap evaluasi dan kesimpulan. 
Ability : Journal of Education and Social Analysis

Volume 2, Issue 4, Oktober 2021

Page : 31-41

\section{HASIL DAN PEMBAHASAN}

Kondisi awal pada saat pembelajaran jarak jauh penulis hanya menggunakan aplikasi power point melalui google classroom atau WhatsApp group. Ketika pembelajaran jarak jauh berlangsung lama dikarenakan pandemic covid 19 yang belum berakhir maka pembelajaran tidak menarik lagi bagi peserta didik. Pembelajaran yang seharusnya dilaksanakan interaksi aktif antara pendidik dengan peserta didik, yang bersifat student center, membuat jenuh dan motivasi belajar peserta didik menurun. Hal ini menjadikan tantangan bagi penulis untuk membuat pembelajaran itu menarik, keberhasilan pembelajaran sangat tergantung pada kemampuan pendidik dalam mengelola pembelajaran, salah satunya kemampuan penulis dalam menggunakan media pembelajaran interaktif articulate storyline.

Salah satu media pembelajaran yang dapat membantu pendidik dalam mengajar dan memfasilitasi proses pembelajaran yaitu media pembelajaran interaktif (Priyambodo, et al., 2012). Media interaktif ini bisa dirancang menggunakan program software yaitu Articulate Storyline. Articulate Storyline adalah perangkat lunak yang difungsikan sebagai media komunikasi atau presentasi. Media pembelajaran menggunakan software ini tidak kalah menarik dengan media interaktif lainnya (Purnama \& Asto, 2014). Media interaktif berupa software Articulate Storyline memiliki kelebihan diantaranya adalah tampilan yang simple seperti power point, fiturnya yang lengkap seperti flash sehingga bisa membuat animasi juga (Rianto, 2020). Media interaktif ini juga menyediakan template yang bisa digunakan untuk media interaktif terutama untuk membuat soal tes dan latihan. Selain itu, program tersebut juga memudahkan pengguna untuk publish secara online maupun offline sehingga dapat diformat dalam bentuk CD, word processing, laman personal dan LMS (Ghozali \& Rusmianto, 2016). Media interaktif ini juga dapat membantu dalam penyampaian materi pendapatan nasional yang bersifat abstrak atau sulit

dipahami. Kesulitan belajar dalam mata pelajaran ekonomi salah satunya dikarenakan tidak semua materi dapat dipelajari melalui pengalaman langsung dan penggunaan media yang pasif dan kurang interaktif sehingga peserta didik merasa sulit memahami dan merasa bosan.

Untuk mengatasi permasalahan di atas penulis memberikan sarana media belajar mandiri di rumah dan memfasilitasinya dengan membuat media pembelajaran interaktif articulate storyline yang dapat dibuat format aplikasi android sehingga peserta didik dapat mudah dalam membukanya dan mempelajari materi-materi yang ditampilkan dan latihan soal secara berulang serta terdapat skor nilainya. 
Ability : Journal of Education and Social Analysis

Volume 2, Issue 4, Oktober 2021

Page : 31-41

Untuk mengetahui respon dari peserta didik tentang pembelajaran jarak jauh maka penulis membuat angket yang di berikan kepada peserta didik melalui google form yang diinformasikan dengan WA grup. Dari penyebaran angket tersebut dapat diperoleh data sebanyak 103 respon angket yang telah diisi. Berdasarkan hasil kuesioner yang telah diisi oleh 103 siswa kelas XI SMA Negeri 1 Kabupaten Pandeglang diperoleh data yang di sajikan.

Angket yang disebarkan kepada siswa secara online melalui google form dikirimkan melalui whatsapp group kelas. Penggunaan angket ini bertujuan untuk mendapatkan informasi berupa pelaksanaan proses pembelajaran secara dalam jaringan (daring) dengan menggunakan media pembelajaran Artyculate Storyline. Berikut adalah pertanyaan dan hasil yang diperoleh di dalam angket yang diajukan kepada siswa sebagai berikut :

Tabel 1.

Data Hasil Kuesioner Peserta Didik Kelas XI Penggunaan Media Pembelajaran Interaktif Articulate Storyline pada Materi Pendapatan Nasional.

\begin{tabular}{|c|c|c|c|c|c|}
\hline \multirow{2}{*}{$\begin{array}{c}\text { Nomor } \\
\text { Pernyataan }\end{array}$} & SS & S & RR & TS & STS \\
\hline 1 & 19,42 & 76,70 & 3,88 & 0 & 0 \\
\hline 2 & 20,39 & 71,84 & 7,77 & 0 & 0 \\
\hline 3 & 24,27 & 61,17 & 7,77 & 6,80 & 0 \\
\hline 4 & 13,59 & 60,19 & 23,30 & 2,91 & 0 \\
\hline 5 & 20,39 & 69,90 & 9,71 & 0 & 0 \\
\hline 6 & 13,59 & 74,76 & 11,65 & 0 & 0 \\
\hline 7 & 29,13 & 63,11 & 7,77 & 0 & 0 \\
\hline 8 & 24,27 & 60,19 & 12,62 & 2,91 & 0 \\
\hline 9 & 25,24 & 63,11 & 9,71 & 1,94 & 0 \\
\hline 10 & 15,53 & 70,87 & 13,59 & 0 & 0 \\
\hline
\end{tabular}

\section{Pertanyaan 1 :}

Saya merasa besemangat melaksanakan pembelajaran materi pendapatan nasional dengan media pembelajaran interaktif Articulate Storyline.

Berdasarkan Data, terlihat bahwa siswa lebih banyak menjawab setuju sebesar 76,70 yang berarti bahwa siswa merasa bersemangat mengikuti pembelajaran materi pendapatan nasional dengan media pembelajaran interaktif Articulate Storyline.

\section{Pertanyaan 2:}

Media pembelajaran interaktif Articulate Storyline membantu saya dalam memahami materi pendapatan nasional.

Berdasarkan Data, untuk pernyataan kedua siswa lebih banyak menjawab setuju dengan persentase $71,84 \%$ menunjukkan bahwa media pembelajaran 
Ability : Journal of Education and Social Analysis

Volume 2, Issue 4, Oktober 2021

Page : 31-41

interaktif Articulate Storyline membantu dalam memahami materi pendapatan nasional.

\section{Pertanyaan 3 :}

Media pembelajaran interaktif Articulate Storyline lebih mudah digunakan dalam proses pembelajaran jarak jauh.

Berdasarkan Data, siswa lebih banyak menjawab setuju dengan persentase 61,17\% yang berarti bahwa media pembelajaran interaktif Articulate Storyline lebih mudah digunakan dalam proses pembelajaran jarak jauh. 6,80\% siswa menjawab tidak setuju bahwa Media pembelajaran interaktif Articulate Storyline lebih mudah digunakan dalam proses pembelajaran jarak jauh.

\section{Pertanyaan 4:}

Saya merasa lebih mudah memahami materi pendapatan nasional menggunakan media pembelajaran interaktif Articulate Storyline dibandingkan dengan media pembelajaran lain.

Dilihat dari Tabel 1, hasil yang diperoleh juga sama seperti pernyataan ketiga yaitu siswa lebih banyak setuju dengan persentase 60,19\% dan sebanyak 2,91\% tidak setuju bahwa lebih mudah memahami materi pendapatan nasional menggunakan media pembelajaran interaktif Articulate Storyline dibandingkan dengan media pembelajaran lain.

\section{Pertanyaan 5:}

Saya merasa termotivasi saat guru menjelaskan materi pendapatan nasional dengan media pembelajaran interaktif Articulate Storyline.

Berdasarkan Data, siswa lebih banyak menjawab setuju dengan persentase $69,90 \%$ yang berarti bahwa siswa termotivasi dengan pembelajaran.

\section{Pertanyaan 6:}

Saya merasa termotivasi saat mengerjakan latihan soal menggunakan media pembelajaran interaktif Articulate Storyline.

Berdasarkan Data, siswa lebih banyak menjawab setuju dengan persentase $74,76 \%$ yang berarti bahwa termotivasi saat mengerjakan latihan soal menggunakan media pembelajaran interaktif Articulate Storyline.

\section{Pertanyaan 7:}

Media pembelajaran interaktif Articulate Storyline yang diberikan guru memiliki tampilan yang menarik sehingga membuat saya tertarik.

Berdasarkan Data, siswa lebih banyak menjawab setuju dengan persentase $63,11 \%$ yang berarti bahwa media pembelajaran interaktif Articulate Storyline memiliki tampilan yang menarik.

Pertanyaan 8: 
Ability : Journal of Education and Social Analysis

Volume 2, Issue 4, Oktober 2021

Page : 31-41

Media pembelajaran interaktif Articulate Storyline mendukung pembelajaran jarak jauh karena tidak membutuhkan banyak kuota untuk mengaksesnya.

Berdasarkan Data, siswa lebih banyak menjawab setuju dengan persentase 60,19\%, dan sebesar 2,91\% tidak setuju.

\section{Pertanyaan 9:}

Media pembelajaran interaktif Articulate Storyline praktis dan mudah digunakan.

Berdasarkan Data, siswa lebih banyak menjawab setuju dengan persentase 63,11\%, sedangkan sebesar 1,94\% tidak setuju bahwa Media pembelajaran interaktif Articulate Storyline praktis dan mudah digunakan.

\section{Pertanyaan 10:}

Media pembelajaran interaktif Articulate Storyline efektif dalam pembelajaran materi pendapatan nasional.

Berdasarkan Data, siswa lebih banyak menjawab setuju dengan persentase 70,87\% bahwa merasa efektif dalam pembelajaran materi pendapatan nasional dengan media interaktif Articulate Storyline

Berdasarkan pertanyaan nomor 1 dan nomor 5 yang merujuk pada rasa bersemangat dan menambah motivasi belajar siswa terhadap penggunaan media pembelajaran interaktif Articulate Storyline, didapatkan hasil setuju dengan persentase yang paling tinggi yaitu 76,70\%, hasil ini menunjukkan bahwa siswa merasa bersemangat dan memilki motivasi belajar yang tinggi saat guru menggunakanan media pembelajaran interaktif Articulate Storyline.

Media pembelajaran interaktif Articulate Storyline memiliki fitur yang beragam sehingga guru dapat berkreasi membuat media pembelajaran yang menarik. Sejalan dengan pertanyaan nomor 6 dengan persentase 74,76 siswa setuju, dan nomor 7 didapatkan hasil dengan persentase 63,11 \% siswa setuju bahwa media pembelajaran interaktif Articulate Storyline yang dikirimkan guru menarik, juga mampu untuk memvisualisasikan materi rumus, video, dan latihan soal yang interaktif.

Pertanyaan nomor 8 memperoleh hasil 60,19\% siswa setuju bahwa penggunaan media pembelajaran interaktif Articulate Storyline mendukung pembelajaran jarak jauh.pertanyaan ini didukung dengan pertanyaan nomor 9 dan 10 yaitu media pembelajaran interaktif Articulate Storyline tidak banyak membutuhkan kuota untuk mengaksesnya, media pembelajaran interaktif Articulate Storyline juga praktis, dan mudah digunakan serta efektif dalam pembelajaran. 
Ability : Journal of Education and Social Analysis

Volume 2, Issue 4, Oktober 2021

Page : 31-41

Media pembelajaran interaktif Articulate Storyline dikatakan efektif digunakan, pendapat ini didukung dengan hasil penelitian Fitri (2021) menyatakan bahwa pemanfaatan Articulate Storyline sebagai media pembelajaran interaktif dapat meningkatkan motivasi belajar dan dinyatakan efektif karena berada pada tingkat efektivitas tinggi. Menurut Setyaningsih (2020) penggunaan media pembelajaran interaktif Articulate Storyline berpengaruh terhadap motivasi belajar dan hasil belajar peserta didik.

Media pembelajaran interaktif Articulate Storyline mampu menunjang pembelajaran jarak jauh, agar pelaksanaan proses pembelajaran menjadi lebih mudah disampaikan. pembelajaran jarak jauh dilakukan pada masa pandemic COVID-19 saat ini. Penggunaan media pembelajaran interaktif Articulate Storyline dianggap media yang paling memungkinkan untuk menunjang terlaksananya pembelajaran agar tujuan pembelajaran juga tetap tercapai.

Menurut Fitriyah (2020) media pembelajaran interaktif Articulate Storyline dapat digunakan sebagai sumber belajar dan pendukung pembelajaran jarak jauh. Juga membantu memudahkan penyampaikan materi dengan tambahan fitur kompetensi, kuis, video pembelajaran, dan glosarium yang dapat diakses secara offline serta kemudahan pengunduhan pada web yang telah disediakan.

Oleh karena itu penggunaan media pembelajaran interaktif Articulate Storyline menjadi media yang relevan untuk dikembangkan khususnya di masa pandemi. Kekuatan media pembelajaran interaktif Articulate Storyline terletak pada penulisan isi yang efektif, variasi penggunakan berbagai gambar dan animasi, latihan menjawab pertanyaan, penambahan suara audio yang lebih menyenangkan, sehingga dapat menjadi sesuatu yang menarik bagi peserta didik. 
Ability : Journal of Education and Social Analysis

Volume 2, Issue 4, Oktober 2021

Page : $31-41$

Tabel 2.

Data Hasil Penilaian Pembelajaran Tidak menggunakan Media Pembelajaran Interaktif Artyculate Storyline dengan Data Hasil Penilaian Menggunakan Media Pembelajaran Interaktif Artyculate Storyline.

\begin{tabular}{|c|c|c|c|c|}
\hline No & Nama Siswa & $\mathbf{L} / \mathbf{P}$ & Nilai 1 & Nilai 2 \\
\hline 1 & ACHMAD AZMI ALDI NUGRAHA & $\mathrm{L}$ & 87 & 87 \\
\hline 2 & ADE RAHAYU & $\mathrm{P}$ & 80 & 83 \\
\hline 3 & AHMAD & $\mathrm{L}$ & 47 & 40 \\
\hline 4 & ALVIA FEBIOLA & $P$ & 77 & 77 \\
\hline 5 & AMANDA ALYATUL HIFZIAH & $\mathrm{P}$ & 77 & 90 \\
\hline 6 & AULIA PUTRI LUTFIAH & $\mathrm{P}$ & 87 & 90 \\
\hline 7 & DELLA AGMI AGNESA TAPALAS & $\mathrm{P}$ & 87 & 87 \\
\hline 8 & DIKI DARMAWAN & $\mathrm{L}$ & 87 & 100 \\
\hline 9 & DINDA ANANTA PUTRI ROHYADI & $P$ & 17 & 43 \\
\hline 10 & ĖLA SULISTIAWATI & $\mathrm{P}$ & 83 & 80 \\
\hline 11 & FELIA NAGITA CHERIEL & $\mathrm{P}$ & 80 & 83 \\
\hline 12 & HANIFAH ALYA HUWAIDA & $\mathrm{P}$ & 80 & 87 \\
\hline 13 & HILDA RAHMA DINI SIREGAR & $P$ & 87 & 77 \\
\hline 14 & KARINA SARILLA GUCI & $P$ & 97 & 100 \\
\hline 15 & MIRNA WULANDARI & $\mathrm{P}$ & 73 & 73 \\
\hline 16 & MOCHD. ZULFIKAR ARIYA LUTFI & $\mathrm{L}$ & 90 & 100 \\
\hline 17 & MUCHAMAD MAULANA WIDJAYA & $\mathrm{L}$ & 87 & 87 \\
\hline 18 & MUHAMAD ANDREAN NUGRAHA & $\mathrm{L}$ & 77 & 83 \\
\hline 19 & MUHAMAD RAFI FADLY & $\mathrm{L}$ & 90 & 97 \\
\hline 20 & MUHAMMAD FAZRUL FALAH BAJURI & $\mathrm{L}$ & 17 & 37 \\
\hline 21 & MUHAMMAD RAIHAN KZ & $\mathrm{L}$ & 87 & 93 \\
\hline 22 & MUHAMMAD ZAQI ALMURTADHO & $\mathrm{L}$ & 87 & 87 \\
\hline 23 & NABILA FAIZA & $P$ & 73 & 73 \\
\hline 24 & NAZWA PUTRI FADILLAH & $\mathrm{P}$ & 77 & 80 \\
\hline 25 & NESSHA NIDHYA KURNIA PUTRI & $\mathrm{P}$ & 83 & 77 \\
\hline 26 & REISYIFA INDRIA SETIANI & $P$ & 67 & 73 \\
\hline 27 & RIFA LELY LESTARI & $P$ & 77 & 80 \\
\hline 28 & RIZKIA AMALI & $\mathrm{L}$ & 40 & 47 \\
\hline 29 & RT FUJI YUNIA LESTARI & $\mathrm{P}$ & 93 & 90 \\
\hline 30 & RT. NAYLA DIBA AYU PUTRI & $\mathrm{P}$ & 63 & 70 \\
\hline 31 & SARI RAHMAH & $P$ & 87 & 90 \\
\hline 32 & SIFA AULIA AGUSTIN & $\mathrm{P}$ & 77 & 87 \\
\hline 33 & SILVI OKTAVIANI & $\mathrm{P}$ & 53 & 53 \\
\hline 34 & SITI SRI ASTUTI & $\mathrm{P}$ & 37 & 47 \\
\hline 35 & SOFIA AYU KIRANA & $P$ & 87 & 100 \\
\hline 36 & TITA PUSPITA & $P$ & 77 & 83 \\
\hline 37 & TRI MAULANA & L & 93 & 87 \\
\hline 38 & TRIANI SULISTIA & $\mathrm{P}$ & 60 & 73 \\
\hline 39 & VANESSA AGUSTINA NUGROHO & $\mathrm{P}$ & 53 & 43 \\
\hline
\end{tabular}


Ability : Journal of Education and Social Analysis

Volume 2, Issue 4, Oktober 2021

Page : $31-41$

\section{Keterangan :}

- Nilai 1 adalah data hasil penilaian pembelajaran tidak menggunakan media pembelajaran interaktif articulate storyline.

- Nilai 2 adalah data hasil penilaian pembelajaran menggunakan media pembelajaran interaktif articulate storyline.

Hasil penilaian peserta didik melalui test tertulis yang dilaksanakan melalui daring menggunakan media google forms dari tabel 2 dapat di peroleh keterangan, bahwa ada kenaikan hasil antara pembelajaran yang menggunakan media pembelajaran interaktif articulate storyline dengan pembelajaran yang tidak menggunakan media pembelajaran interaktif articulate storyline yaitu kenaikan sebesar 5,39\% dari data Nilai 1 dengan rata-rata 74 dan data Nilai 2 dengan rata-rata 78 .

Wawancara juga dilakukan oleh penulis dengan mengambil sampel tiga orang peserta didik yang ditanya langsung oleh penulis dengan hasil wawancara sebagai berikut; penulis memberikan pertanyaan, Bagaimana pendapat anda setelah mengikuti pembelajaran jarak jauh dengan media pembelajaran Artyculate storyline materi pendapatan nasional ? jawaban peserta didik yang pertama, responden pertama menjawab, bahwa pembelajaran dengan media pembelajaran articulate storyline seru mengasyikan, seperti quis dan merasa bisa. Responden kedua, dengan jawaban, pembelajaran mudah dimengerti, bisa diulang berkali-kali dan asyik. Serta responden ketiga dengan jawaban, merupakan inovasi baru, unik dan mudah dipahami.

\section{KESIMPULAN}

Dari hasil penelitian ini dapat disimpulkan bahwa media pembelajaran interaktif articulate storyline relevan digunakan dalam pembelajaran materi Pendapatan Nasional di SMA Negeri 1 Kabupaten Pandeglang. Media pembelajaran ini juga memudahkan peserta didik dalam pembelajaran jarak jauh di masa Pandemi COVID 19 karena sifatnya yang praktis, mudah digunakan, efektif, dan tidak memerlukan banyak kuota untuk mengaksesnya. Hasil pembelajaran menggunakan media pembelajaran interaktif articulate storyline secara umum dapat meningkatkan semangat pembelajaran, memahami materi, menarik sebagai media pembelajaran serta dapat meningkatkan kompetensi penilaian. Dari hasil penilaian harian materi pendapatan nasional mengalami peningkatan sebesar 5,39\% yang sudah mencapai ketuntasan kompetensi minimum dengan nilai rata-rata 78 setelah menggunakan media pembelajaran interaktif Artyculate storyline. Penulis juga 
Ability : Journal of Education and Social Analysis

Volume 2, Issue 4, Oktober 2021

Page : 31-41

membuat media pembelajaran interaktif articulate storyline dan menerapkannya dalam pembelajaran.

\section{PENGAKUAN/ PENGHARGAAN}

Ini adalah teks singkat untuk mengakui kontribusi kolega, institusi, atau lembaga tertentu yang membantu upaya penulis.

\section{REFERENCES}

Adhetya, C.,Iin, D. L \& Sari, P.D.L, 2020. Motivasi Belajar Siswa SMA pada Pembelajaran Daring di Masa Pandemi Covid-19. Jurnal Pendidikan Islam, (online), vol.3 no.01, (https:// doi.org/10.37542/iq.v3i01.57, diakses 2020)

Amiroh, 2021. Kenapa harus Artyculate Storyline?

(https://amiroh.web.id/kenapa-harus-articulate-storyline/ diakses tanggal 24 Januari 2021).

Azzahra, Abidin, Susiati, dan Cahyadi, 2021. Tantangan dan Upaya Guru SMA dalam Melaksanakan Pembelajaran Jarak Jauh. Lectura: Jurnal Pendidikan, Vol.12 No. 2, Agustus 2021.

Cecep, K \& Bambang, S, 2011. Media Pembelajaran Manual dan Digital. Jakarta: Ghalia Indonesia.

Fina,S., M.Muttaqina.,Idad, S., Dindin, J \& Epa, P, 2021. Artyculate Storyline: Sebuah Pengembangan Media Pembelajaran Interaktif Pada Materi Sel. Jurnal Ilmiah Pendidikan,(online), vol.05 no.01 (http:/ /journal.unpak.ac.id/index.php/pedagonal diakses 21 April 2021)

Husein dan Ibrahim, 2021. Pengembangan Media Pembelajaran Interaktif Menggunakan Articulate Storyline Di Sekolah Dasar. Jurnal Ilmu Pendidikan Non Formal, Vol 07, (03), 2021.

Indiani B, 2020. Mengoptimalkan Proses Pembelajaran Dengan Media Daring Pada Masa Pandemi COVID-19, (online), vol 1 no.3

Kurniasari, Pribowo, dan Putra, 2020. Analisis Efektifitas Pelaksanaan Belajar Dari Rumah (BDR) Selama Pandemi COVID-19. Jurnal Kajian Pendidikan dan Hasil Penelitian. Vol 6, No 3, September 2020.

Muzzamil F, 2021. Peran Orang Tua Sebagai Guru Pengganti di Rumah Pada Saat Anak Pembelajaran Jarak Jauh (PJJ) Selama COVID-19. Jurnal Ilmu Pendidikan.

Pusat Data dan Teknologi Informasi Pendidikan dan Kebudayaan. 2020. Pembuatan Multimedia Interaktif. Jakarta: Kementerian Pendidikan dan Kebudayaan. Modul Pembelajaran Berbasis TIK (PembaTIK). Level Kreasi. 
Ability : Journal of Education and Social Analysis

Volume 2, Issue 4, Oktober 2021

Page : $31-41$

Setyaningsih, Rusijono, dan Wahyudi, 2020. Pengaruh Penggunaan Media Pembelajaran Interaktif Berbasis Artyculate Storyline Terhadap Motivasi Belajar dan Hasil Belajar Siswa Pada Materi Kerajaan Hindu Budha Di Indonesia. Jurnal Pendidikan dan Ilmu Pengetahuan Vol.20 No.2 Tahun 2020.

Sukmarini, Mauludiah, Roziqi, dan Nurdianto, 2021. Pemanfaatan Articulate Storyline 3 sebagai Media Pembelajaran Interaktif untuk meningkatkan Motivasi Belajar Bahasa Arab Siswa. al Mahāra Jurnal Pendidikan Bahasa Arab, Vol. 7, No.1, Juni 2021/1442H.

Yasmini, 2021. Meningkatkan Motifasi Belajar Siswa Melalui Layanan Bimbingan Covid Berbasis Zozizz. Indonesian Journal of Educational Development Volume 2 Nomor 1, Mei 2021.

Yuangga dan Sunarsi, 2020. Pengembangan Media Dan Strategi Pembelajaran Untuk Mengatasi Permasalahan Pembelajaran Jarak Jauh di Pandemi COVID- 19. Vol. 4 No. 3 Juni 2020.

Zaitun, Winata, dan Yudhistira, 2020. Problematika serta Strategi Penerapan Pembelajaran Jarak Jauh Berbasis Teknologi di Masa Pandemi Covid-19. Prosiding Seminar Nasional Penelitian LPPM UMJ. 